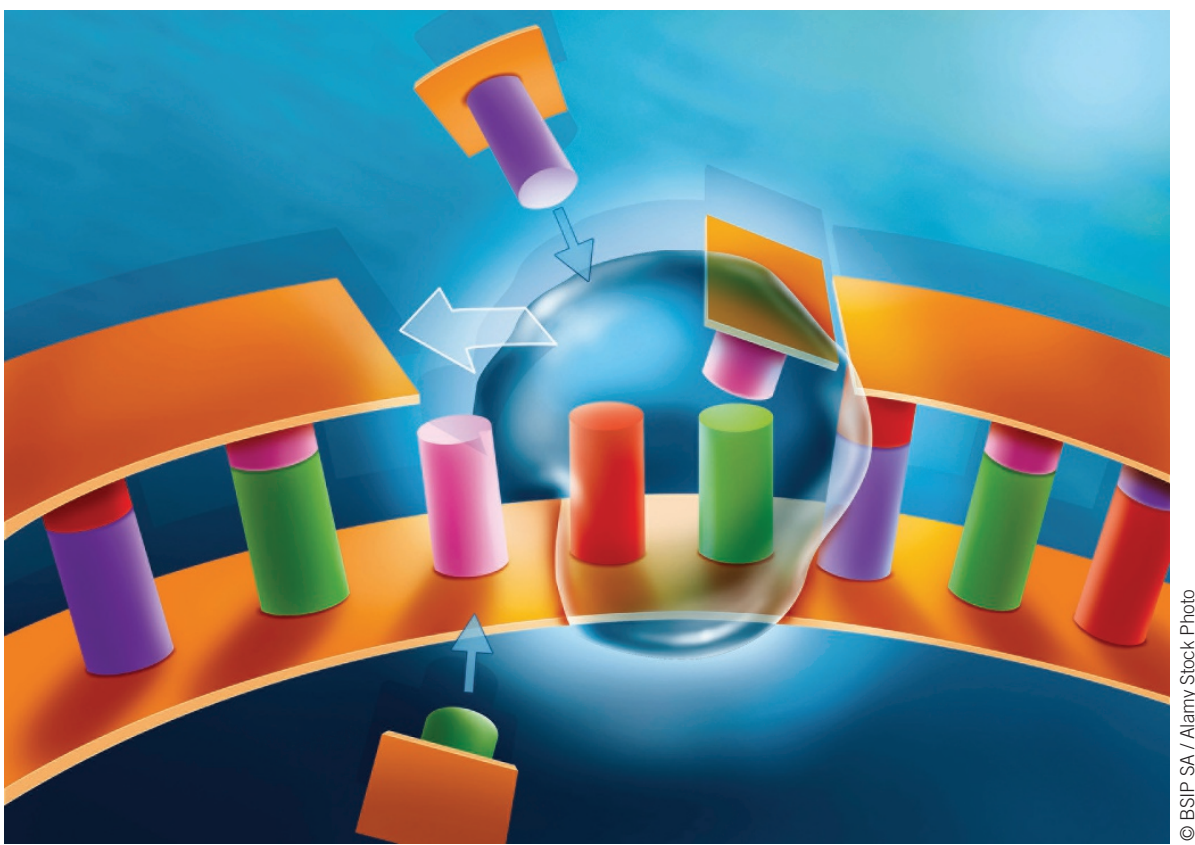

Adding subtle alterations to the pig genome could provide a source of organs for human transplants.

For more complex constructs, DNA sequences will have to be stitched together into chromosomes, overlaid with the right epigenome, and inserted into cells and nuclei. There are certainly techniques to stitch together large pieces of DNA, and scientists have already developed artificial human chromosomes and the means to insert them into certain cells. But the processes require improvement, and understanding how chromosome sequences are involved in centrosome attachment, segregation and stability remains a work in progress. "If I had to identify the biggest bottleneck, it would be... delivery of big DNA efficiently, intact, precisely to the right place," says Boeke. "This is going to be where we need some serious technology development."

Scientists could also make subtler alterations across an organism's genome. For example, researchers have long eyed pigs as a possible source of organs for human transplantation. Recoding the pig genome could eliminate pig antigens associated with rejection. David Cooper, a transplant immunologist at the University of Pittsburgh Medical Center, says he and others have already made progress with pigs containing only a handful of genetic modifications. They've achieved survival upwards of a year for monkeys with pig pancreatic islets, and he is already starting to consider what kinds of patients would make good candidates for xenotransplantation trials. "We are virtually there already," says Cooper. "We don't need to take radical steps now."
Time will tell whether a killer app will emerge for the project. "We probably haven't thought of the most powerful applications yet," says Boeke.

But if HGP-Write seeks to catalyze a drop in the cost of DNA synthesis, it may have missed the boat. Claes Gustafsson, cofounder of DNA2.0, in Newark, California, points out that the price of DNA synthesis already dropped from dollars to cents over the past decade, without a concomitant bioengineering revolution. Drew Endy, a bioengineer at Stanford University in California, and cofounder of DNA synthesis company Gen9 in Cambridge, Massachusetts, agrees that the notion that HGP-Write will lead to a precipitous reduction in price per base "falls flat." "From an economic perspective the HGPWrite proposal is, ironically, ten years too late," says Endy. "It could have made a massive difference to industry back when gene synthesis costs were around \$1 per base pair."

At the moment, DNA synthesis averages about 20 cents per base pair and can go as low as just a few cents for large quantities. Scientists can order pieces up to about $10 \mathrm{~kb}$ in length, or even longer for a premium, Emily Leproust, CEO and cofounder of Twist Bioscience in San Francisco, says. To build the three-billion base human genome, at today's lowest prices (two to three cents/base pair), would probably run $\$ 60-90$ million. Leproust notes, "DNA will become cheaper anyway, with or without this project."

Amber Dance Los Angeles

\section{Gilead's first pan-genotypic HCV cure}

The US Food and Drug Administration (FDA) approved the first drug combination to treat the majority of people infected with chronic hepatitis $\mathrm{C}$ virus (HCV). Epclusa from Gilead Sciences of Foster City, California, is a single-tablet, fixed-dose combination of the previously approved Sovaldi (sofosbuvir), a nucleotide analog HCV NS5B polymerase inhibitor, and velpatasvir (GS-5816), a pangenotypic HCV NS5A protein inhibitor. The agency gave the green light to Epclusa to treat people infected with all six genotypes of HCV without cirrhosis. The FDA based its decision on phase 3 ASTRAL studies in 1,035 subjects with genotype 1-6 chronic HCV infection, in which Epclusa produced a sustained virologic response lasting 12 weeks in $98 \%$ of individuals. The combination achieved high cure rates across all HCV genotypes, including genotypes 2 and 3 , which traditionally have required ribavirin. Gilead said Epclusa's wholesale acquisition cost (WAC) will be $\$ 74,760$ for a 12 -week course. The big biotech markets Sovaldi at a WAC of $\$ 84,000$ per 12-week course to treat HCV genotypes 1-4. Its other HCV combo therapy, Htarvoni (ledipasvir/sofosbuvir), costs $\$ 94,500$ per course and is approved to treat HCV genotypes $1,4,5$ and 6 . For people with moderate to severe cirrhosis, the FDA approved Epclusa in combination with ribavirin. Epclusa's label includes a warning addressing the risk of bradycardia when Epclusa is used in combination with the antiarrhythmic drug amiodarone. The FDA had granted Epclusa a priority review and breakthrough therapy designation. The combination drug is Gilead's third Sovaldi-based product.

\section{6 "I have seen the beginning of what I fear will be a huge headache} for Vermonters and for a lot of smaller stores as well...supplies of baby formula, affordable canned fruit and vegetables, and many other items will be sold out and unavailable. This law was a bad idea from the ground up and now Vermonters are going to have to pay the price." Vermont resident Shannon @DinoReaderMom documents the consumer reality of Vermont's labeling law going into effect. (Biofortified Blog, 7 July 2016) 